\title{
Interactive roles of mesograzers and current flow in survival of kelps
}

\author{
David Duggins ${ }^{1, *}$, James E. Eckman ${ }^{2}$, Christopher E. Siddon ${ }^{3}$, Terrie Klinger ${ }^{4}$ \\ ${ }^{1}$ Friday Harbor Laboratories, 620 University Road, University of Washington, Friday Harbour, Washington 98250, USA \\ ${ }^{2}$ Office Naval Research, 800 North Quincy Street, Arlington, Virginia 22217-5660, USA \\ ${ }^{3}$ Ecology and Evolutionary Biology, Brown University, Providence, Rhode Island 02912, USA \\ ${ }^{4}$ School of Marine Affairs, University of Washington, 3707 Brooklyn Ave. N.E., Seattle, Washington 98105-6715, USA
}

\begin{abstract}
The relationship between hydrodynamic energy and biological processes is examined for a kelp-dominated marine community in the San Juan Archipelago. Populations of a common and widely distributed kelp, Nereocystis luetkeana, were established and rates and causes of mortality followed at 7 sites differing greatly in tidally driven current velocities and wave exposure (measured by permanently deployed instrument packages). Mortality of $N$. luetkeana was not related to storm energy, but exhibited a significant non-linear relationship with tidal current energy such that mortality rates were highest at sites exhibiting protracted periods of calm punctuated by episodes of strong currents. The role of mesograzers (primarily the gastropod Lacuna vincta) on survivorship in these kelp populations was evaluated in the field and in laboratory flume experiments. The relationship between grazer damage and stipe breaking force was investigated by measuring the tensile forces required to break experimentally damaged stipes. Although undamaged stipes can easily withstand the tensile forces imposed by even the strongest current and wave exposures, a very small amount of damage will have highly significant negative effects on breaking strength. While apparently responsible for a significant portion of $N$. luetkeana mortality in low and variable energy environments, $L$. vincta is unable to persist on kelp stipes in high-energy environments and its role there is trivial. The relationship between $L$. vincta grazing and hydrodynamic energy is however nonlinear, because water movement has opposite effects on grazer foraging behavior and the drag forces imposed on kelps, and this results in a complex relationship between hydrodynamic energy and kelp survival. We suggest a conceptual model for relating kelp survival to grazing intensity in hydrodynamically variable environments. The model leads to the prediction, exhibited in our field results, that the probability of plant mortality may be maximized in regions of intermediate flow energy.
\end{abstract}

KEY WORDS: Kelp $\cdot$ Nereocystis $\cdot$ Hydrodynamics $\cdot$ Population dynamics $\cdot$ Lacuna

\section{INTRODUCTION}

The population dynamics of benthic marine organisms are controlled by a complex suite of biological and physical processes. However, the interaction between these 2 factors can produce non-intuitive results and complicates the construction of predictive models regarding population and community structure. While clearly important, such interactions have received considerably less scrutiny by field and theoretical ecolo-

*E-mail: dduggins@u.washington.edu gists than has the role of a given factor in isolation. For example, the marine ecological literature is rife with studies of the role of predation and herbivory in communities, and the isolated influence of physical factors on individual performance (e.g., growth, production, reproduction). What is generally lacking is a consideration of how physical factors influence the behavior, efficiency, and ultimately the role of consumers (but see Witman \& Grange 1998, Sanford 1999). Perhaps the most notable exception is studies on the relationship between wave exposure and the influence of benthic consumers. But even here, results are contradic- 
tory and generalizations elusive. Menge (1978a,b) and Peterson (1979) found a negative relationship between wave exposure and the importance of consumers in structuring the intertidal in the northwestern Atlantic, but Robles (Robles \& Robb 1993, Robles 1997) found the opposite when examining lobster predation in southern California. Negative correlations between wave exposure and consumer effect have been observed for tropical urchins (Foster 1987) and temperate urchins (Kawamata 1998), while no relationship was observed between exposure and herbivory in South African intertidal structure (McQuaid \& Branch 1985).

The role of benthic grazers in controlling marine algal populations is well understood in a number of communities, particularly the role of echinoids in both temperate and tropical systems. The importance of hydrodynamics to algal population dynamics has received less attention, and the interaction between hydrodynamics and grazer effects is poorly understood. Several studies have examined mortality in kelp populations (order Laminariales) caused by hydrodynamic disturbance (sensu Grime 1981) following catastrophic or atypically severe storm events, and severe hydrodynamic energy is clearly a major source of mortality for both surface canopy (Koehl \& Wainwright 1977, Dayton \& Tegner 1984, Seymour et al. 1989, Utter \& Denny 1996) and understory (Black 1976, Santelices et al. 1980, Ebling et al. 1985, Kennelly 1987) kelps. Survival can be affected by the 'strength' of the alga or the object to which the macrophyte is attached (Black \& Peterson 1987). It is also clear from laboratory studies on kelp breaking strength and field measurements of drag on kelp thalli in high flows (current speeds or wave accelerations) that the breaking strength of undamaged kelp tissues greatly exceeds the forces to which they are subjected even under the most energetic circumstances. However, damaged tissues in the holdfast or stipe can cause these structures to exhibit significantly lower breaking strengths (Black 1976, Koehl \& Wainwright 1977, Denny et al. 1989, DeWreede et al. 1992, Friedland \& Denny 1995, Tegner et al. 1995, Utter \& Denny 1996).

Clearly, both herbivory (including non-lethal herbivory that compromises structures that provide benthic attachment) and flow energy are important determinants of algal survivorship. However, the interaction between these 2 factors could affect a plant population in several ways. For example, constant exposure to strong flows could lead to a strengthening (toughening) of algal tissue, which in turn could deter herbivory by making plant tissues less edible. On the other hand, higher flow energy could directly increase the rate of failure of algal structures such as holdfasts and stipes, or dislodge their anchoring substrates, and failures in these structures inevitably lead to removal from the population. Flow could also have indirect effects on algal populations via its effects on grazer behavior or efficiency. The increased drag on macrophytes in stronger flow environments may also be imparted to their grazers and may represent a significant risk to them.

In this paper we examine the relationship between hydrodynamic environment and population dynamics of an abundant kelp in the northeastern Pacific. Nereocystis luetkeana is found in a wide range of habitats, from fully wave-exposed to moderately wave-protected, and it occupies a broad geographical distribution, from the Aleutian Islands, Alaska, to central California. An annual or biannual alga, N. luetkeana is common in disturbed rocky habitats and is frequently one of the first macrophyte species to colonize a shallow subtidal area denuded by grazers or physical disturbance. Surprisingly, given its distribution and abundance, little is known about $N$. luetkeana population dynamics (Maxell \& Miller 1996). In this paper we examine survivorship in $N$. luetkeana populations at 7 sites with very different hydrodynamic characteristics. The interaction of herbivory and hydrodynamics results in a pattern of mortality that may well be a general phenomenon for algae throughout the intertidal and shallow subtidal zones.

\section{METHODS}

Study sites and hydrodynamic properties. Seven study sites in the San Juan Archipelago (Fig. 1, Table 1) were chosen to include a broad range of hydrodynamic regimes (incorporating variability in both tidal currents and wind-generated waves). The hydrodynamic properties of each study site were assessed using a suite of identical in situ instrument complexes, each of which measured temperature, pressure (depth and wave signals), and current speed and direction. Each sensor in

Table 1. Characteristics of study sites. Current velocity: $1=$ always strong; 2 = always weak; 3 = variable (see 'Discussion')

\begin{tabular}{|c|c|c|c|}
\hline Site (abbreviation) & $\begin{array}{l}\text { Current } \\
\text { velocity }\end{array}$ & $\begin{array}{l}\text { Wave } \\
\text { exposure }\end{array}$ & $\begin{array}{c}\text { Nereocystis } \\
\text { luetkeana } \\
\text { survival }\end{array}$ \\
\hline Brown Island (B) & 3 & Protected & Low \\
\hline Cantilever Point (C) & 2 & Protected & Intermediate \\
\hline Long Island (L) & 3 & Exposed & Low \\
\hline Minnesota Reef (M) & 1 & Protected & High \\
\hline Reid Rock (R) & 1 & Protected & High $^{a}$ \\
\hline Whale Rocks (W) & 1 & Exposed & High \\
\hline Yellow Island (Y) & 3 & Protected & Low \\
\hline
\end{tabular}


the instrument complex was wired to a battery-powered microcomputer placed inside watertight pressure housing. The relatively low cost of these instrument packages allowed us to simultaneously and continuously deploy replicate units at each site. Further details regarding design and operation of these instruments will be discussed in a forthcoming paper.

All in situ measurements, observations and experiments occurred on nearly horizontal rock platforms at depths ranging from 6.8 to $11.0 \mathrm{~m}$. Instruments were attached to the rock substratum using anchor bolts placed in small areas (several $\mathrm{m}^{2}$ ) kept clear of kelps by divers. Instruments were programmed to record temperature, pressure and currents at $2 \mathrm{~Hz}$ for $128 \mathrm{~s}$ every $15 \mathrm{~min}$ at approximately $30 \mathrm{~cm}$ above the substratum, a height closely matching elevations of thalli of understory kelps. The 2 min average current speed and direction, temperature, and pressure (translatable to depth) were recorded every $15 \mathrm{~min}$. In addition, the microcomputer was programmed to examine the pattern of the $2 \mathrm{~Hz}$ pressure fluctuations and to record all the measurements of currents and pressure (translatable to instantaneous wave signals) if pressure fluctuations indicated an influence of waves at depth. The threshold for a wave 'event' (that triggered recording of high-frequency data) was exceeded if the rootmean-square pressure fluctuation exceeded the standard deviation of a sine wave with an amplitude (at depth) of $28.3 \mathrm{~cm}$ (equivalent to a pressure fluctuation of $2.83 \times 10^{4} \mathrm{dyn} \mathrm{cm}^{-2}$ ). At these depths, storm-generated pressure fluctuations produced a monochromatic wave pattern with a period of typically 5 to $6 \mathrm{~s}$. Linear wave theory predicts that pressure signals of that amplitude, at $8 \mathrm{~m}$ depth and with a period of $5 \mathrm{~s}$, would be associated with maximum horizontal flow speeds of $26 \mathrm{~cm} \mathrm{~s}^{-1}$. This is less than the maxima in tidal current speeds at most sites (see 'Results'). Therefore, this threshold ensured that all important wave-dominated flows were recorded.

At least 2 instruments were deployed at each site throughout the duration of the Nereocystis luetkeana population studies. This meant that influences of storm-generated waves were well characterized at each site. In addition, to more fully characterize hydrodynamic variability within each site due to topographically produced variability in exposure, 2 to 3 additional instruments were deployed within each site for a period of several weeks. These additional meters were rotated among sites throughout the study period so that local variability in currents was measured at all sites. The deployment of 4 to 5 instruments for several weeks within each site ensured that most of the variability in the spring-neap cycle of the mixed semidiurnal tide was absorbed. Therefore, flow variability both within and among sites was well characterized.

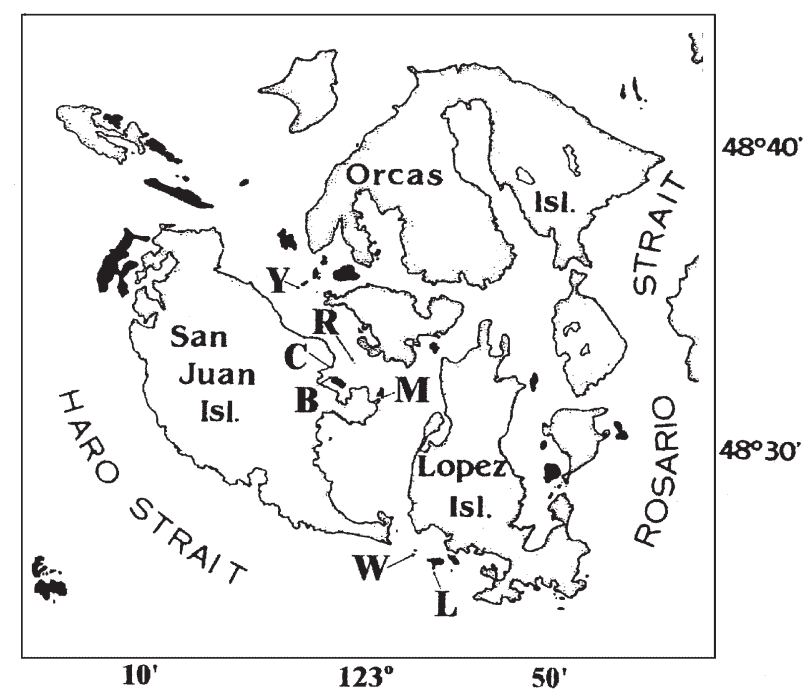

Fig. 1. Map of San Juan Archipelago showing locations of the 7 study sites identified by single-letter codes: B: Brown Island, C: Cantilever Point, L: Long Island, M: Minnesota Reef, R: Reid Rocks, W: Whale Rocks, Y: Yellow Island

Several hydrodynamic statistics pertinent to Nereocystis luetkeana population dynamics were extracted from the instrument data. First, the 95th and 99th percentile of the 2 min average current strength is reported for each site from the instrument that recorded the strongest current signals (i.e., the instrument in the most exposed location of all the replicate instruments). The most exposed instrument was selected because $N$. luetkeana rapidly grows beyond shadowing effects of local topography to lengths exceeding water depth (even at high tide, the pneumatocyst may not be directly above the holdfast). The maximum flow statistics reported by our instruments significantly underestimate currents experienced by the kelps because the majority of the alga biomass resides at or near the sea surface (where current velocities are greater than our measured near-bottom values). However, these statistics should accurately reflect the relative variability in current signals among sites. Second, for each site, using the instrument from the most exposed locale, a frequency distribution of 'duration of calm' was generated. Duration of calm is defined as the interval during which mean current speed remains below a threshold value, selected as $20 \mathrm{~cm} \mathrm{~s}^{-1}$. This threshold and frequency distribution may relate to the ability of mesograzers (gastropods and isopods) to forage on and damage N. luetkeana stipes. Third, maximum flow speeds generated by storm waves at depth are reported for each site. Data are reported for 3 intervals during fall 1995 through spring 1996. These intervals were defined by the times 
of retrieval and re-deployment of the instrument complexes. Recovery and re-deployment of meters was necessitated by the limited life of battery packs ( 2 to 3 mon). However, since a replacement meter was deployed at the same time each meter was retrieved, there were no gaps in coverage during the deployment period.

Outplant experiments. To assess the survivorship of Nereocystis luetkeana at sites differing in hydrodynamic characteristics, small sporophytes (less then $1.0 \mathrm{~mm}$ total length) were outplanted to 6 sites (C, B, L, M, W, and Y) in early August 1995. N. luetkeana is known to exhibit broad and predictable morphological variation along hydrodynamic gradients (Koehl \& Alberte 1988), and while much of this variation may reflect environmentally mediated plasticity, the possibility exists that limited spore dispersal could result in genetically distinct populations in this species. In order to assure genetic similarity among outplanted populations at all sites, fertile sori were collected from $10 \mathrm{~N}$. luetkeana sporophytes at Minnesota Reef (Site M). Sori were mildly desiccated at $10^{\circ} \mathrm{C}$ for several hours to encourage spore release. Spores were released from each sorus separately into $500 \mathrm{ml}$ sterile seawater. After release, suspensions of swimming spores from all 10 parents were mixed. This provided us with a single stock culture of limited genetic diversity.

The stock culture was maintained in Alga-gro ${ }^{\circledR}$ medium, in a vegetative state at $8^{\circ} \mathrm{C}$ at an irradiance of $60 \mu \mathrm{E} \mathrm{m}^{-2} \mathrm{~s}^{-1}$ and a day length of 16:8 h (light:dark), for several months. The medium was changed bi-weekly, and was unialgal but not axenic. Inocula were prepared for outplanting to field sites by removing vegetative gametophytes from this stock culture and pulverizing for $45 \mathrm{~s}$ in a pre-cooled Waring ${ }^{\circledR}$ blender in which the cutting blade had been replaced with a double-edged razor blade (this procedure is widely used to induce sexuality among kelp gametophytes). The filament fragments produced were then equally apportioned among 6 culture vessels, where they settled onto several hundred small (1 cm diameter) roughened plastic substrates ('discs') loosely attached to a plate in the bottom of each vessel. These cultures were then held under the same culture conditions as above for about $2 \mathrm{wk}$, after which time they were checked for the presence of gametangia and small (microscopic) sporophytes. Once gametangia and sporophytes were observed, all discs were outplanted to field sites over the course of $6 \mathrm{~d}$.

In the field, the discs were fixed to the substrate (using epoxy) in a water depth of approximately $8 \mathrm{~m}$. Discs were placed every $1 \mathrm{~m}$ along 2 or 3 parallel transect lines spaced 1 to $2 \mathrm{~m}$ apart. Prior to outplanting, all sites (measuring approximately $200 \mathrm{~m}^{2}$ ) had been cleared of benthic macroalgae and moderate-to-large grazers (primarily sea urchins of the genus Strongylocentrotus). Subsequently, sites were kept free of urchins and other macroalgae to eliminate their effect on Nereocystis luetkeana survivorship. A total of 242 discs was outplanted, each containing numerous microscopic sporophytes. Approximately 1 mo after outplanting, each disk was thinned to a single 2 to $3 \mathrm{~cm}$ (total length) kelp, thus establishing an even-aged, experiment-wide population of nearly homogeneous genetic stock. This thinning event, which occurred in early September of 1995, signified the beginning of the outplanting survivorship census.

Following thinning, all individuals at each site were censused every 3 to $4 \mathrm{wk}$ for the following $306 \mathrm{~d}$ (at the end of which time all had disappeared). At every census the presence or absence of each individually numbered plant was scored and, if absent, the cause of mortality (holdfast, stipe, or blade failure) was evaluated based on evidence of remnant tissue. Because there was a 3 to $4 \mathrm{wk}$ period between censuses, we were concerned that loss or decay of remnant tissue might contribute to error in identifying the location of failure. To evaluate this possible census artifact, we randomly selected 20 naturally occurring Nereocystis luetkeana at Long Island (Site L) and cut their stipes $2 \mathrm{~m}$ above the substrate. We followed the remaining holdfast and stipe remnant weekly over the next $4 \mathrm{wk}$ to evaluate whether the holdfast was subsequently lost.

To compare survival of Nereocystis luetkeana among sites, data regarding proportion of plants surviving as a function of time were fitted to an exponential decay function, which fit empirical data well. The model used was:

$$
N(t) / N_{0}=\exp (-\lambda t)
$$

where $N(t)$ is the number of plants alive at Time $t, N_{0}$ is the original number of plants, and $\lambda$ is the mortality rate. $\lambda$ was estimated by regression analysis - it is the slope of the best linear fit of $\ln \left(N(t) / N_{0}\right)$ vs $t$, with the intercept forced through the origin at $t=0\left(\ln \left(N(t) / N_{0}\right)\right.$ $=0$, or $\left.N(t) / N_{0}=1\right)$. Because the comparisons were of interest a priori, best-fit estimates of $\lambda$ were compared among sites using least-significant difference (LSD) multiple comparisons tests (Sokal \& Rohlf 1981).

Transplant experiment. Beginning in late October 1996, a second evaluation of Nereocystis luetkeana survivorship was conducted at all 7 sites (B, C, L, M, R, $\mathrm{Y}$ and $\mathrm{W}$ ) utilizing a common garden technique. Juvenile plants with undamaged stipes and with a total stipe length (holdfast to pneumatocyst) of 3 to $4 \mathrm{~m}$ were collected at Whale Rocks (Site W). These individuals were transplanted to the 7 sites (including back to W) by attaching them to the holdfasts of mature Laminaria bongardiana (a species with a particularly tenacious 
holdfast). The $L$. bongardiana stipe was severed just above the holdfast and the $N$. luetkeana holdfast was attached to the remaining $L$. bongardiana holdfast using cable ties threaded between the two. We refer to these plants as 'transplants' rather than 'outplants' (as in the experiment previously described). Surveys of these transplanted populations were conducted weekly for $45 \mathrm{~d}$. At each census, every plant was scored for its presence or absence, and number and type of grazers on each remaining stipe.

The number of plants transplanted to each site was too small (averaging 10.4) to permit mortality data to be fit to an exponential decay model, as was used in the outplant experiment. Instead, data from each site were used to compute a mean and variance of plant survival time which was compared among sites using ANOVA.

Study of grazing in current flow. During the course of field operations in 1995, we censused grazers on Nereocystis luetkeana stipes utilizing haphazardly selected, naturally occurring, transplanted and outplanted $N$. luetkeana.

In addition, to investigate the relationship between current velocity and grazer activity on Nereocystis luetkeana stipes, we collected small (1 to $2 \mathrm{~m}$ total stipe length) plants from Reid Rocks (Site R), and secured them to the runway of a large racetrack flume. The main channel of this flume was $8 \mathrm{~m}$ long, $0.7 \mathrm{~m}$ wide; and water depth was kept at $20 \mathrm{~cm}$. To standardize experiments, a constant angle of about $60^{\circ}$ between the substrate and lower stipe was achieved by draping plants over a stationary object located just below the water surface and downstream of the attachment point. All measurements were made on this lower portion of the stipe. Before flow was initiated in the flume, 4 or 5 Lacuna vincta were placed on the stipe and allowed to acclimate for $10 \mathrm{~min}$. L. vincta, a small herbivorous gastropod, is the only significant grazer on $N$. luetkeana stipes at all of our study sites (see 'Results'). Water in the flume was then accelerated in steps of $3.1 \mathrm{~cm} \mathrm{~s}^{-1}$ every 2 min until a velocity of $96 \mathrm{~cm}$ $\mathrm{s}^{-1}$ was reached (64 min). This rate of acceleration was chosen to mimic that following slack current (zero current velocity) at a moderately high current site (e.g., Site M), as determined by our instrument packages. Flume velocity was continuously measured using a Marsh McBirney electromagnetic flow meter deployed mid-channel. When velocity reached $96 \mathrm{~cm} \mathrm{~s}^{-1}$ it was held constant until all grazers were removed from the stipe by the flow or had crawled off the stipe. Ten different stipes and 164 snails were used over the course of this experiment. For each snail we noted the number of minutes after acceleration began that it was able to remain on the stipe, and from this we were able to calculate the water velocity when each 'detachment' occurred. As a control for this experiment, we repeated the above procedure but rather than accelerating flow to $96 \mathrm{~cm} \mathrm{~s}^{-1}$, it was accelerated to $3.0 \mathrm{~cm} \mathrm{~s}^{-1}$ and held constant for $6 \mathrm{~h}$, thus creating a constant, very low-flow environment. This control flow regime was chosen because all sites in the study region experience at least some minimal tidal currents, and thus zero flow would have been unrealistic.

Breaking strengths and drag forces on Nereocystis luetkeana. We investigated the breaking strength of stipes, the effects of grazing on breaking strength, and the tensile force experienced by stipes at different flow velocities. Plants ranging in size from 18 to $4200 \mathrm{~g}$ wet wt (0.2 to $7.3 \mathrm{~m}$ stipe length) were collected from Reid Rocks (Site R). We dragged the plants through the water at a constant speed abeam a small motor boat (Koehl \& Wainwright 1977) to determine the drag experienced by the plants, and the consequent tensile force experienced by their stipes. A recording spring scale was attached in line between the stipe and a heavy lead weight suspended from the boat's davit. We measured the alga drag at a velocity of $2.0 \mathrm{~m} \mathrm{~s}^{-1}$, a speed higher than flows measured at our highest current rate but similar to instantaneous velocities measured at our higher wave-exposure sites. The alga was deployed just below the surface and abeam of the boat (rather than astern) to avoid surface and wake turbulence. Acceleration to $2.0 \mathrm{~m} \mathrm{~s}^{-1}$ was slow and constant. Speed through the water was determined accurately using an electromagnetic flow meter (Marsh McBirney Inc., Frederick, Maryland, USA).

Measurement of Nereocystis luetkeana stipe breaking strength was conducted on a range of plant sizes (also collected from Reid Rocks). Kelps were kept moist in wet burlap bags after collection, and all measurements were carried out in air within $2 \mathrm{~h}$ of collection. Each plant was laid out along a dock and the pneumatocyst was secured to an immovable object. The holdfast was connected to a recording tensometer, which was in turn secured to a winch. Each plant was stretched (applying force at a constant rate) until it broke, and the breaking strength was recorded.

To simulate the effects of grazing on breaking strength, we made identical measurements on plants whose stipes were subjected to very shallow cuts $(0.5$ or $1.0 \mathrm{~mm}$ depth). Cuts were made using a razor blade attached to, and projecting beyond, the edge of a small plastic block. One such cutting block was constructed for each cutting depth. The block was drawn in a straight line past the stipe in a direction tangential to the surface of the stipe, resulting in a shallow, short cut. This arrangement allowed us to carefully control the depth of the cut. We damaged all stipes at the point of their minimum cross-sectional diameter (which occurs near the base of the stipe), where the vast 
Table 2. Strengths of tidal current and storm wave driven velocities recorded $20 \mathrm{~m}$ above the bottom at each site. nd: no data

\begin{tabular}{|c|c|c|c|c|c|c|c|}
\hline & $\begin{array}{l}\text { Brown } \\
\text { Island }\end{array}$ & $\begin{array}{c}\text { Cantilever } \\
\text { Point }\end{array}$ & $\begin{array}{l}\text { Long } \\
\text { Island }\end{array}$ & $\begin{array}{c}\text { Minnesota } \\
\text { Reef }\end{array}$ & $\begin{array}{c}\text { Reid } \\
\text { Rocks }\end{array}$ & $\begin{array}{l}\text { Whale } \\
\text { Rocks }\end{array}$ & $\begin{array}{l}\text { Yellow } \\
\text { Island }\end{array}$ \\
\hline 95th percentile current speed $\left(\mathrm{cm} \mathrm{s}^{-1}\right)$ & 24.4 & $<10$ & 38 & 54.8 & 111 & 64.1 & 39.9 \\
\hline 99th percentile current speed $\left(\mathrm{cm} \mathrm{s}^{-1}\right)$ & 43.3 & 26.6 & 43.4 & 62.4 & 124 & 73.8 & 48.8 \\
\hline Max. wave speed $\left(\mathrm{cm} \mathrm{s}^{-1}\right): 27 \mathrm{Sep}-5$ Dec 95 & 0 & 0 & 151 & 0 & nd & 197 & 54 \\
\hline 5 Dec $95-6$ Mar 96 & 0 & 0 & 133 & 0 & nd & 147 & 0 \\
\hline 6 Mar - 3 May 96 & 0 & 0 & 96 & 0 & nd & 131 & 0 \\
\hline
\end{tabular}

majority of undamaged stipes fails (see 'Results cause of failure'). For each plant we recorded the minimum stipe diameter, the position on the stipe where failure occurred, the force required to break the plant, the mass of the holdfast, stipe, and entire plant, and the plant's total length.

\section{RESULTS}

\section{Hydrodynamic characteristics of sites}

Three of the sites ( $\mathrm{M}, \mathrm{R}$ and $\mathrm{W})$ experience consistently strong tidal currents, although currents at Reid Rocks (R) stand out as being exceptionally strong (Table 2). Tidal currents at B, L and Y are intermediate in strength, though each experiences currents in excess of $40 \mathrm{~cm} \mathrm{~s}^{-1}$ (20 cm above bottom) regularly (i.e., at some point during the spring-neap tidal cycle). Tidal flow at Cantilever Point (C) is uniquely weak. More than 95\%

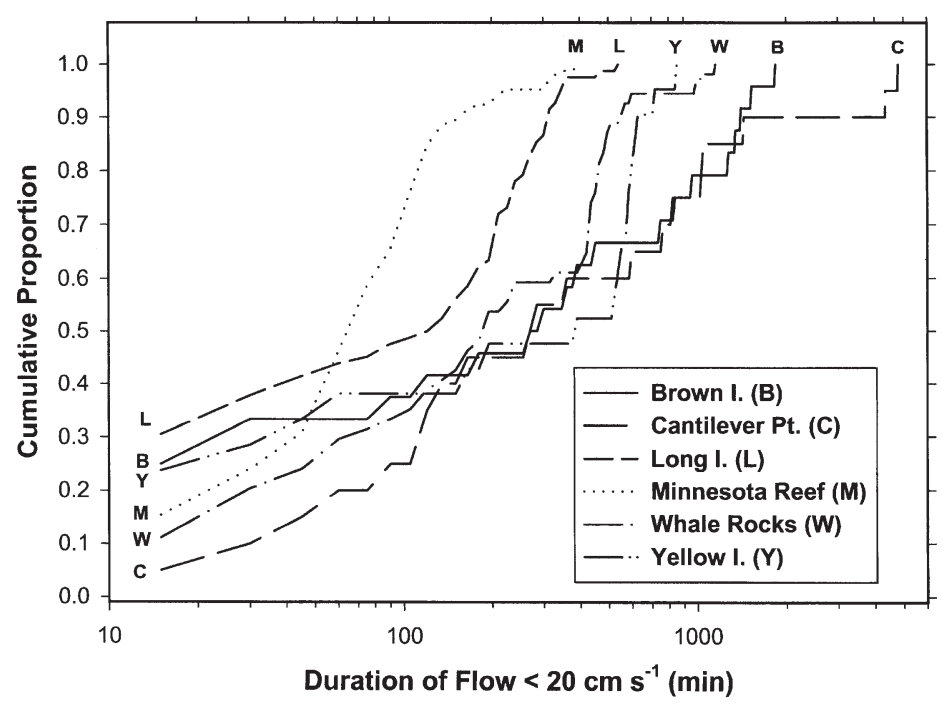

Fig. 2. Cumulative probability distributions of 'duration of calm' - the length of time that flow remained $<20 \mathrm{~cm} \mathrm{~s}^{-1}$ during the period $25 \mathrm{Sep}$ tember to 6 December 1995 at the 6 sites where the outplant experiment was performed of the time current velocities at Cantilever are below the detection threshold $\left(\sim 10 \mathrm{~cm} \mathrm{~s}^{-1}\right)$ of the instruments used.

Periods of 'calm flow' (i.e. $<20 \mathrm{~cm} \mathrm{~s}^{-1}$ ) tended to be relatively brief at Minnesota Reef (M), with $50 \%$ of these periods lasting less than 60 min (Fig. 2). Periods of calm at Long Island (L) tended to last twice as long as at Minnesota Reef. Three other sites (B, W and Y) were protected by topography during part of the tidal cycle, and all experienced sustained periods of calm flow (Fig. 2) despite exposure to moderate (B, Y) or strong (W) currents during other parts of the tidal cycle. At these 3 sites, $50 \%$ of calm periods lasted $>3 \mathrm{~h}(\mathrm{~W})$ to $>5 \mathrm{~h}$ (Sites B, Y). Cantilever Point experienced the longest duration of calm flow, as expected given the generally weak currents there.

Of the 7 sites 5 are located inside San Juan Channel and are significantly protected from wind-generated waves by the proximity of San Juan Island to the west. At 7 to $11 \mathrm{~m}$ depth, an influence of waves was never recorded at 3 of these 5 sites (B, C, M: Table 2). Only once during the winter of 1995/1996 were wave effects noted at depth off Yellow Island (Site Y). At that time the maximum combined current plus wave speed measured $30 \mathrm{~cm}$ above bottom reached $54 \mathrm{~cm} \mathrm{~s}^{-1}$ (Table 2). Instruments were not deployed at Reid Rocks (Site R) simultaneously with those at the other sites, so comparable wave data there are not available, but given its position in San Juan Channel (Fig. 1) wave speeds should be minimal, probably most similar to patterns recorded at Yellow Island. In contrast, the 2 sites located outside San Juan Channel ( $\mathrm{L}$ and $\mathrm{W}$ ) were unprotected to the south and west, and were subjected to strong storm-wave effects on several occasions during the winter of 1995/1996. Maximum current plus wavegenerated velocities at Whale Rocks ranged from 131 to $197 \mathrm{~cm} \mathrm{~s}^{-1} 30 \mathrm{~cm}$ above the bottom. At Long Island, combined current plus wave velocities were somewhat less (96 to $151 \mathrm{~cm} \mathrm{~s}^{-1}$ ) than at Whale Rocks, but were still far in excess of tidal current velocities at all sites except Reid Rocks (Table 2). 


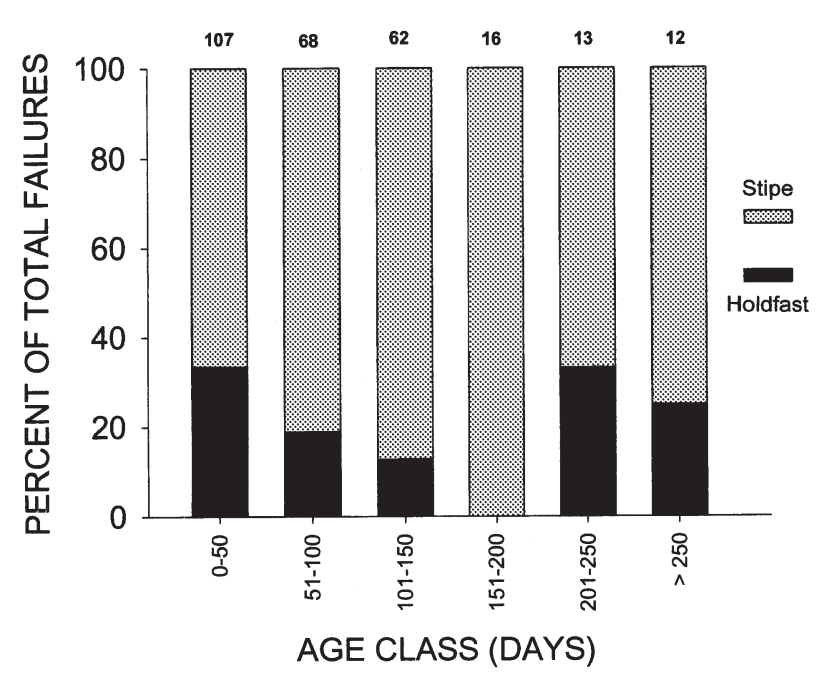

Fig. 3. Nereocystis luetkeana. Locations of plant failures as a function of size class recorded during the outplant experiment. Data from all 6 outplant sites were pooled. Sample size is given above each bar

\section{Cause of failure}

Of the 20 Nereocystis luetkeana plants whose stipes were cut to assess how remnant tissue would survive during the period between censuses, all the holdfasts and stipe remnants remained for the $4 \mathrm{wk}$ observation period. We are thus confident that our assessment of stipe vs holdfast failures in the outplanted populations are accurate (i.e. the disappearance of an entire individual would have been scored as a holdfast failure). We followed fates of 278 plants from birth (outplanting) to death (disappearance from outplanted populations). None of the plants failed following senescence or failure of blade or pneumatocyst tissue. The majority of failures $(77 \%$, Fig. 3) resulted from breakage of the stipe, with breaks usually occurring in the vicinity of the stipe's minimum cross-sectional diameter. The proportion of holdfast failures was highest in the youngest and oldest age classes $\left(\chi_{0.05,5}^{2}=11.26, \mathrm{p}<0.05\right)$.

\section{Nereocystis luetkeana mortality}

From fall 1995 to spring 1996, mortality rates of outplanted Nereocystis luetkeana ranged among sites from a low of $0.0089 \mathrm{~d}^{-1}$ at Whale Rocks to a high of $0.0232 \mathrm{~d}^{-1}$ at Yellow Island (Fig. 4). Regression coefficients for the calculated mortality rate fit the raw data well, and varied among sites from $r^{2}=0.88$ to 0.99 . Multiple comparisons of regression coefficients indicate that mortality rates at Sites $\mathrm{M}$ and $\mathrm{W}\left(0.012 \mathrm{~d}^{-1}\right)$ were low, and each significantly different from those at all other sites (Fig. 4). The mortality rate at Cantilever Point was of intermediate magnitude $\left(0.0157 \mathrm{~d}^{-1}\right)$, and significantly different from that at all other sites except Brown Island. Mortality rates at Sites B $\left(0.0194 \mathrm{~d}^{-1}\right)$ and L and Y $\left(0.021 \mathrm{~d}^{-1}\right)$ were comparatively high and statistically indistinguishable from each other.

Mortality rates co-varied among sites in a significant, non-linear relationship with the strength of tidal currents (Fig. 5). A 2nd-order polynomial regression (defining a parabola) between mortality rate and the 95th percentile of current speed was statistically significant $\left(\mathrm{r}^{2}=0.90\right.$, $\mathrm{p}=0.033$ ) and showed a convex-upward pattern, with mortality rate maximal at an intermediate intensity of tidal current. There was no relationship between kelp mortality rate and exposure to waves. Mortality rates were vastly different at the 2 sites experiencing significant wave energy (L and W: Fig. 4).

The survivorship pattern among sites was similar in both the outplant and transplant experiments with the exception of patterns observed at Sites L and M (see 'Discussion'). In the transplant experiment (Fig. 6), all observed mortalities were the result of stipe failures. This is not surprising given that the size of plants we chose for this experiment (3 to $4 \mathrm{~m}$ stipe length) corresponds to an age class (approximately $150 \mathrm{~d}$ ) for which nearly $100 \%$ of mortality in the outplant experiment was due to stipe failure (Fig. 3). At one site (Y), disap-

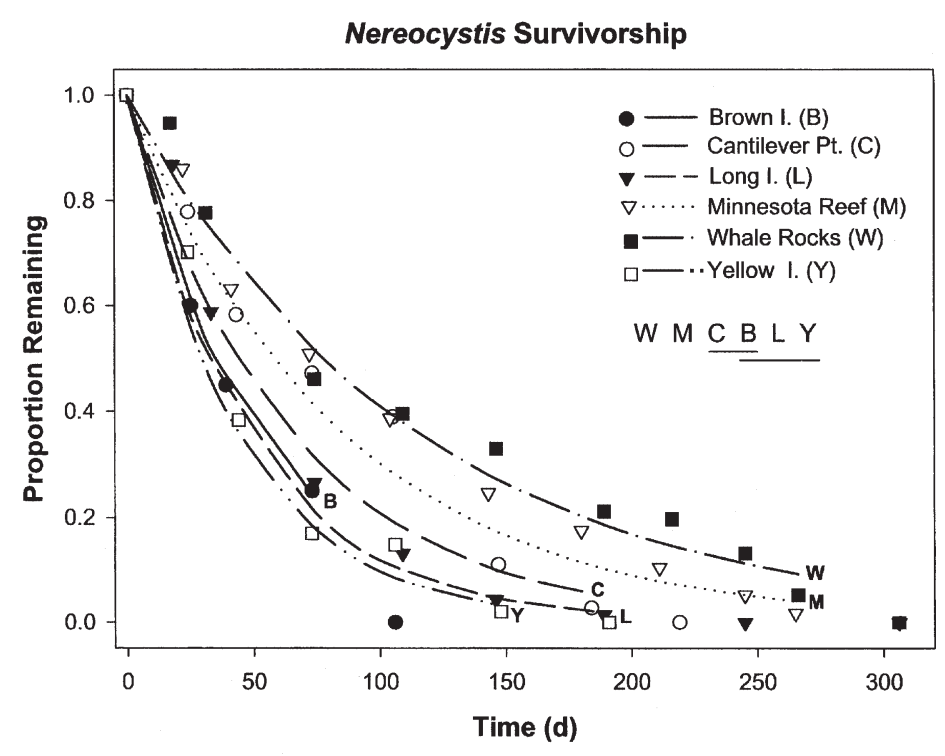

Fig. 4. Nereocystis luetkeana. Proportion of outplanted kelp surviving at each site as a function of time. Lines illustrate best-fit exponential mortality curve for each site, and extend only to time periods used in regression analysis. Shown below site key are results of multiplecomparisons tests for differences among sites in the best-fit mortality rate (lowest mortality on extreme left, highest mortality on extreme right); site codes linked by a common underline are not significantly different: $p>0.05$ 


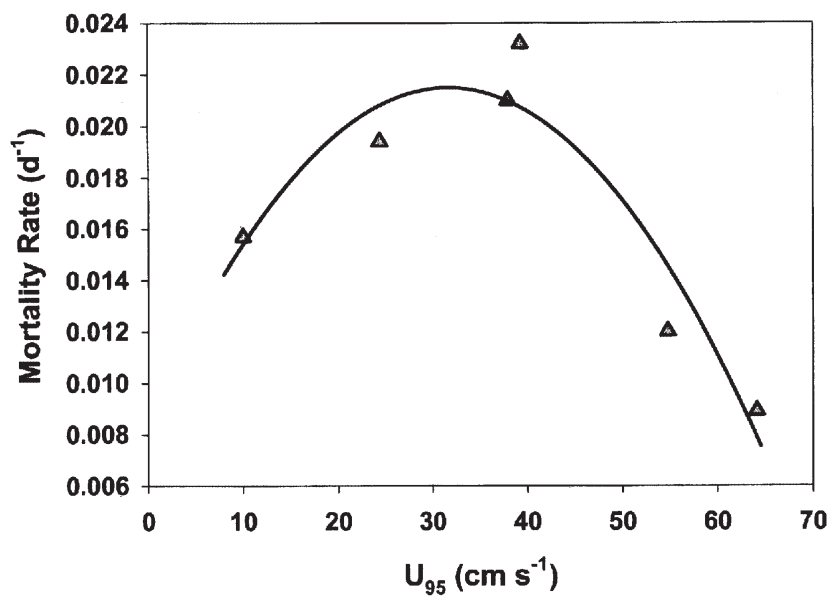

Fig. 5. Nereocystis luetkeana. Best-fit mortality rate calculated for the 6 sites in outplant experiment as a function of the 95th percentile of tidal current speed $\left(U_{95}\right)$ at that site. Line illustrates 2nd-order polynomial that best fits the data

pearance in the transplant experiment was so rapid that only 1 of 8 individuals was remaining when we made our first post-transplant census (after $8 \mathrm{~d}$ ). For purposes of analysis and graphics, we assigned a 'days-survived' value of $8 \mathrm{~d}$ to these 7 individuals. Even with these exaggerated values, Site Y had the highest mortality (lowest survival) rate. While there were significant differences among transplant sites $(F=4.4, \mathrm{p}=0.0008, \mathrm{df}=6,66)$, the sample size in this experiment was small, and pair-wise comparisons of sites seem ambiguous and are, in our opinion, unwarranted. Transplant survival was highest at the 3 sites with highest wave or current energy (W, L and R), and, as in the outplant experiment, was intermediate at the

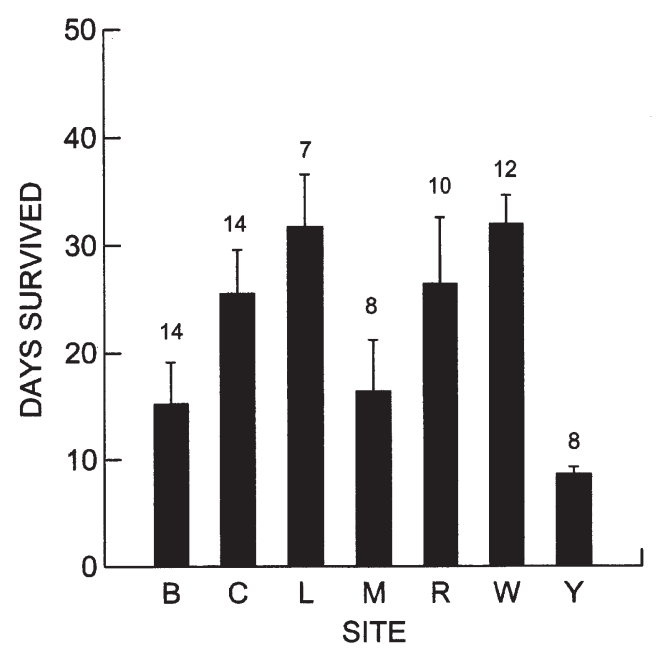

Fig. 6. Nereocystis luetkeana. Mean number of days kelp survived at each site in the transplant experiment. Error bars indicate $\pm 1 \mathrm{SE}$. Sample size is given above each bar. Site designations as in Fig. 1 site with constantly low current velocities and no waves (C). Nereocystis luetkeana at 2 sites (B, Y) exhibited poor survival in both experiments. Both of these sites have highly variable current velocities with comparatively long periods of low current (lasting 5 to $12 \mathrm{~h}$, or more, Fig. 2) followed by bursts of high speed.

Plants transplanted to Long Island (L) experienced relatively long survival, whereas plants outplanted there disappeared relatively rapidly. We attribute this inconsistency to the difference in season when these 2 experiments were performed (see 'Discussion'). At Minnesota Reef (a consistently high-current, lowexposure site), the outplanted population experienced high survival whereas in the transplant experiment survival was poor.

\section{Grazer censuses}

The results of censuses of grazers on outplanted, transplanted, and naturally occurring Nereocystis luetkeana are illustrated in Fig. 7. Of 1118 grazers observed on 277 N. luetkeana stipes, 1047 (94\%) were Lacuna vincta. Additional taxa observed on stipes included Margarites pupillus, Calliostoma ligatum (both gastropods), and Idotea sp. (an isopod). In both the field and laboratory we observed $L$. vincta to be the only significant excavator of $N$. luetkeana stipes. The other 2 gastropod taxa were not seen to inflict significant damage to stipes in the field, and we have too few observations on the isopod to confidently assess its impact. The results of these censuses are unambiguous: at sites with consistent or frequent periods of very high current velocities (B, L, M, R, W) comparatively few grazers ( $L$. vincta) are found on $N$. luetkeana stipes (Fig. 7). It must be noted that for safety reasons, diving at all study sites in this region was conducted during

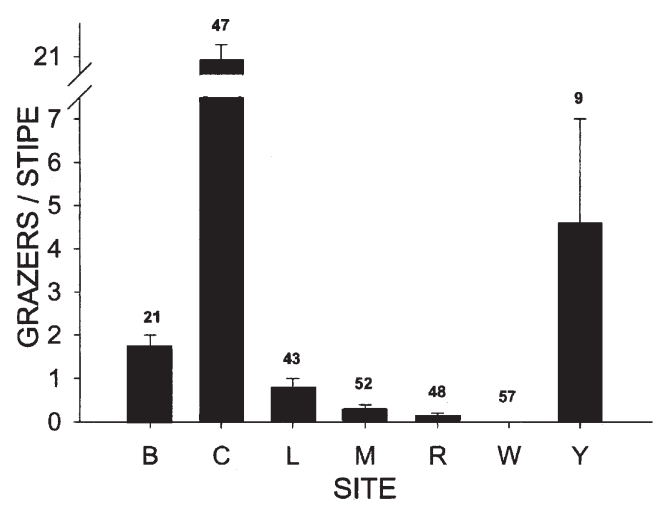

Fig. 7. Mean number of mesograzers (94\% Lacuna vincta, plus Margarites pupillus, Calliostoma ligatum and Idotea sp.) per Nereocystis luetkeana stipe at each site. Error bars indicate \pm 1 SE. Number of stipes examined is given above each bar 


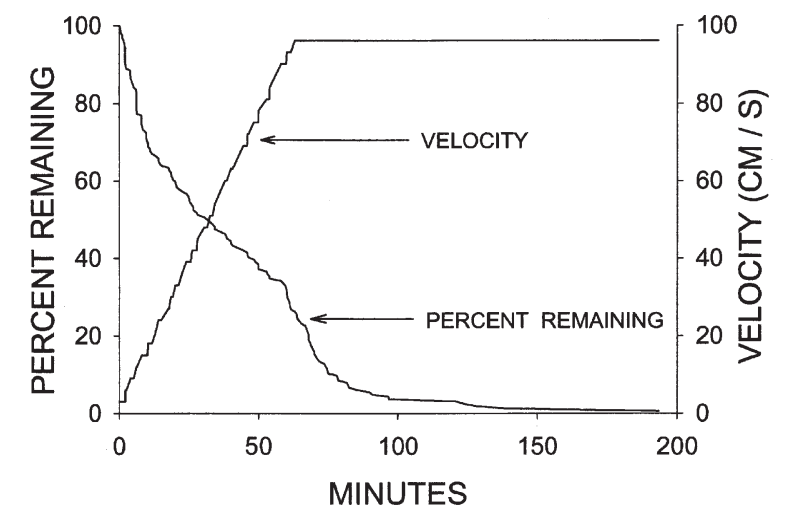

Fig. 8. Temporal pattern of flow velocity and percent of grazers (Lacuna vincta) remaining on Nereocystis luetkeana stipes in the flume experiment

periods of low current. This introduced a conservative bias into our grazer observations. As seen from the flume experiment (below), grazers do not (or cannot) remain on stipes during periods of high flow. Yet they are capable of rapidly moving up and down the stipes during periods of low current velocity. Consequently, by diving during periods when currents were minimal, we were censusing the high-current sites during the only (relatively brief) periods when grazers could persist on stipes. This bias would tend to reduce estimates of differences in grazer densities among sites, yet these differences remain obvious. While we did not attempt to quantify differences among sites in the overall density of Lacuna vincta populations (on and off $N$. luetkeana stipes), they occurred at all sites. Furthermore, at all sites we observed that $N$. luetkeana stipes which had broken or lost their pneumatocyst flotation, and consequently were lying along the substrate, were being consumed by numerous L. vincta.

\section{Flume and breaking-stress experiments}

The flume experiment clarifies the relationship between ambient current velocity and Lacuna vincta persistence on Nereocystis luetkeana stipes (Fig. 8). The control for this experiment is not illustrated because none of the 24 snails tested was removed by the constant $3.0 \mathrm{~cm} \mathrm{~s}^{-1}$ current or crawled down the stipe to the holdfast within $200 \mathrm{~min}$. The flume experiment in which flow was accelerated produced results very different from this control. Even though the rate of acceleration and maximum current were well below those observed at some sites during periods of high tidal exchange, removal of grazers from the experimental stipes was rapid in each experiment. Of the 164 individuals followed during this experiment $50 \%$ disappeared from stipes in the first $30 \mathrm{~min}$ (during which current velocity had risen to only $50 \mathrm{~cm} \mathrm{~s}^{-1}$ ). Most (approximately 80\%) of the snails were gone by the time velocity reached a maximum at $96 \mathrm{~cm} \mathrm{~s}^{-1}$.

The data from our measurements of drag and breaking strength are shown in Fig. 9. Regression lines were fitted through the 4 data sets representing, as functions of plant biomass: (1) tensile force (drag) on an entire plant at $2.0 \mathrm{~m} \mathrm{~s}^{-1}$ (comparable to the highest instantaneous flows measured at wave-impacted sites), and breaking force of (2) an undamaged plant, (3) a plant with a $0.5 \mathrm{~mm}$-deep cut, and (4) a plant with a $1.0 \mathrm{~mm}$-deep cut. Analysis of covariance indicates homogeneity of slopes ( $p>0.25$; all regressions $\left.\mathrm{r}^{2}>0.81, \mathrm{p}<0.001\right)$ and significant differences among treatments in the $y$-intercepts of the 4 lines $\left(F_{3,106}=\right.$ 49.4, $\mathrm{p}<0.001)$. Least-significant difference (LSD) multiple comparisons tests (utilized because the comparisons were of interest a prior) indicate that: (1) undamaged stipes have uniquely high breaking forces, (2) breaking forces of plants with 0.5 and $1.0 \mathrm{~mm}$ deep cuts are not statistically distinguishable from each other but are lower than those of undamaged stipes, and (3) plants with $1.0 \mathrm{~mm}$ deep cuts have breaking forces indistinguishable from drag forces exerted on plants at flow speeds of $2.0 \mathrm{~m} \mathrm{~s}^{-1}$.

It would seem that Nereocystis luetkeana stipes are 'overbuilt' for the forces they are likely to experience in the waters of the San Juan Archipelago. Undamaged stipes are capable of surviving forces 2 times greater than those produced by storm generated waves (Fig. 9). The measurement of stipe breaking strength of dam-

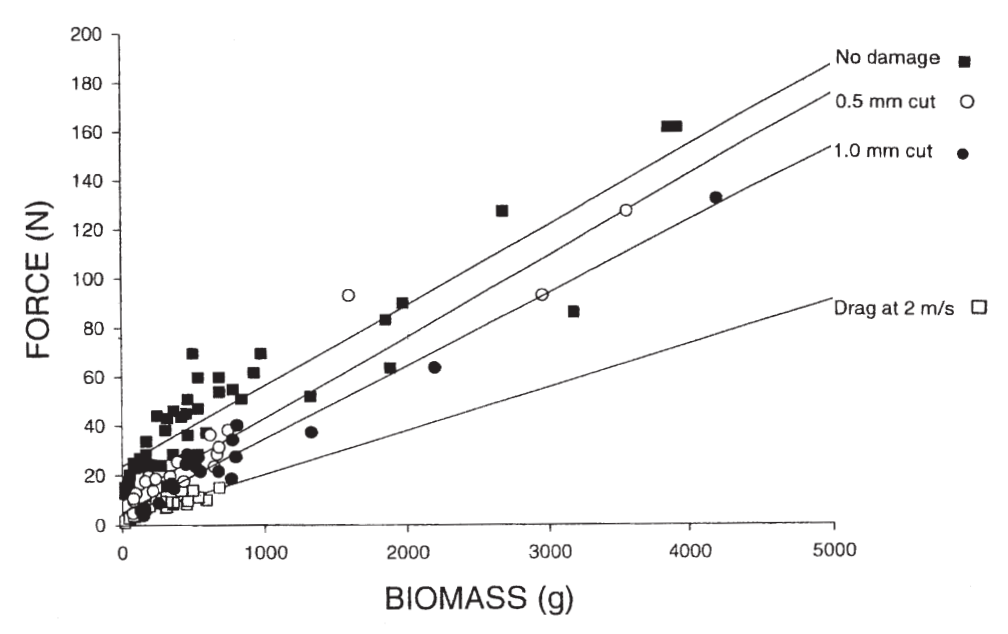

Fig. 9. Nereocystis luetkeana. Breaking forces of undamaged kelp collected from Reid Rocks and of plants damaged by scoring with a razor blade to 2 depths $(0.5$ and $1.0 \mathrm{~mm}$ ) as a function of plant wet biomass. Also shown is drag force on plants towed abeam of a boat at $2 \mathrm{~m} \mathrm{~s}^{-1}$. Lines illustrate best-fit linear regressionsfor each treatment 
aged and undamaged stipes allows us to evaluate the potential for population-level effects of grazing by these small snails. It is obvious that even a very small amount of damage $(0.5 \mathrm{~mm})$ to a stipe results in a significant decrease in strength, although it is not clear from this experiment that damage will reduce breaking forces below those experienced in situ.

\section{DISCUSSION}

Currents and waves can exert tremendous drag forces on benthic organisms in shallow subtidal and intertidal marine habitats. However, the influence of such forces on survivorship in benthic populations is difficult to predict because hydrodynamic forces can act directly on an individual, or indirectly on that individual's consumers or competitors. A widespread example of the interaction between hydrodynamic forces and grazing is found in the very shallow subtidal zone along virtually all wave-exposed, temperate coastlines. From the very low intertidal to a depth (set by wave exposure) of 3 to $10 \mathrm{~m}$, a zone of very high macrophyte abundance and diversity is usually observed. The lower depth limit of this zone is likely to be set by the upper limit of grazing by echinoids. This upper limit on grazing is probably set by the negative influence of wave energy on urchin foraging behavior.

An organism such as Nereocystis luetkeana is clearly capable of surviving drag forces that exceed those found in all but the most extraordinary circumstances. In fact, survivorship is significantly higher at highly energetic sites compared to hydrodynamically more quiescent ones. The outplant and transplant experiments exhibited the same general pattern of plant survival, but rank-order differences do exist among sites that exhibited intermediate rates of mortality (Long Island and Minnesota Reef). Most likely, these differences result from the small sample size in the transplant experiment, but several other factors could have contributed. Firstly, the transplant experiment was short-term and used only large individuals ( 3 to $4 \mathrm{~m}$ long), while the outplant experiment used larger populations of kelps as they grew through their full size range. Hydrodynamic forces will act very differently on individuals of different sizes. Secondly, the data in the outplant experiment reflect a much longer time period. The transplant experiment lasted approximately 1 mo and took place during a period with higher than average wave conditions (fall storms) at Long Island and Whale Rocks, and lower than average tidal exchanges (a recurrent pattern in the San Juan Archipelago in the fall). It is not surprising, given these issues, that there were some differences in intermediate rankings between experiments.
The individual kelps transplanted and outplanted into the most wave-current protected habitats in the San Juan Archipelago grew rapidly and appeared healthy (Duggins pers. obs.), except for a single factor. Individuals in the most protected habitats invariably displayed both large numbers of grazers (Lacuna vincta) on algal stipes, and significant injuries (excavations) attributable to such grazers. At the inception of the outplant experiment we anticipated that a major source of structural failure and algal mortality would result from holdfast failure. This (incorrect) assumption was based on reports in the literature of large numbers of beached Nereocystis luetkeana observed with intact holdfasts (Koehl \& Wainwright 1977), indicating that failure had occurred when holdfasts lost their attachment to the substrate. However, at our 6 outplant sites, holdfast failures never accounted for more than $35 \%$ of mortality in any age class, and $0 \%$ in the modal age class. This is particularly surprising in that older holdfasts are colonized by numerous organisms, some of which can excavate the structure. Holdfast failures do increase in proportion in the oldest age classes, but they reach their highest incidence in the youngest class. We believe that this is due to the failure of many very young individuals ever to establish an adequate attachment to the substrate. We observed many small sporophytes attached to filamentous benthic algae rather than to the substrate, and such attachments are tenuous at best. Garbary et al. (1999) showed that kelp gametophytes are commonly found endophytically in numerous species of filamentous and foliose red algae. In all species of kelps, sporophytes develop directly from the fertilized oogonium on the female gametophytes, so for a plant like $N$. luetkeana, sporophyte growth may begin with a very weak and indirect attachment to the substrate.

The comparatively small number of grazers on algal stipes, or stipe injuries, in the habitats with frequent strong currents appears to result from the inability of grazers to persist on stipes in strong flows. In the flume experiment, Lacuna vincta numbers began declining immediately upon water acceleration. Within $40 \mathrm{~min}$ of the onset of acceleration (at a point where current velocity was $\sim 50 \%$ of maximum velocities observed at high current sites) over half the grazers had been removed from the stipes. The damage imparted by $L$. vincta to Nereocystis luetkeana stipes need not be extreme to have a significant impact on $N$. luetkeana survival. For example a $1.0 \mathrm{~mm}$-deep cut in the stipe of a $2.0 \mathrm{~kg}$ wet weight $N$. luetkeana resulted in a $33 \%$ reduction in stipe breaking strength (Fig. 9). It should be pointed out that the shape of an injury to a kelp structure can itself affect breaking strength. Sharp cuts, such as those we inflicted, are more likely to propagate through stipe tissues under tension than are 
blunt injuries (Denny et al. 1989). Radular grazing by a small gastropod like $L$. vincta may be less 'sharp' than our cuts.

If grazing in the most protected habitats (Cantilever Point) is significantly more intense than at sites with higher ambient current velocities, why did both outplanted and transplanted Nereocystis luetkeana exhibit greater survival at Cantilever than at Brown Island or Yellow Island? We believe the answer to this question is to be found in the magnitude and pattern of current dynamics at these 2 intermediate sites. At Cantilever, current velocity rarely exceeds a magnitude that would affect Lacuna vincta grazing, and consequently virtually all $N$. luetkeana observed at this site exhibit obvious grazer damage. However, because current velocities remain low at all times, hydrodynamic forces imposed upon kelps are very small, and even damaged stipes are able to survive for relatively long periods. The same factor that allows intense grazing (low current) also acts to prolong survivorship by reducing drag on the algal thallus. At sites like Whale Rocks, Reid Rock and Minnesota Reef, extreme current velocities preclude grazing from ever reaching significant levels, and intact stipes are easily able to withstand drag forces, even during the most extreme spring tidal exchanges. N. luetkeana survival was poorest at Brown and Yellow Islands. These sites are characterized by extended periods of relatively low current (Fig. 2), during which time significant grazing can occur. In contrast to Cantilever, both of these sites experience high current velocities during at least part of the spring-neap tidal cycle (Table 2). It is during these periods of high flow that damaged stipes failed.

Within the range of wave and current speeds observed in the San Juan Archipelago, our data suggest that wave exposure has comparatively little effect on Nereocystis luetkeana populations, while current speed is an excellent predictor of kelp survival (Fig. 5). At Long Island and Whale Rocks, 2 sites exposed to heavy westerly wave swells and with comparable max- imum wave speeds, survival in the outplant experiment was very different. These 2 sites differ greatly in both 95th and 99th percentile current speed, suggesting that current, not waves, is important in mediating grazing on stipes (Table 2). Likewise, comparing sites with similar current maxima but very different wavespeed maxima (Minnesota Reef and Whale Rocks), we see similar patterns of comparatively high $N$. luetkeana survival (outplant experiment), again suggesting that current, not waves, was the important variable.

Mesograzing on attachment structures (stipes and holdfasts) is only one of a number of factors affecting population dynamics of benthic macrophytes. It would appear that along very wave- or current-exposed coastlines, mesograzers such as Lacuna vincta may have little or no influence. But an organism such as Nereocystis luetkeana is clearly capable of growing and reproducing in hydrodynamically quiescent habitats, and in these habitats mesograzers seem to play an extremely important role. The relationships among grazing, hydrodynamics, and macrophyte survival are complex because water motion has opposite effects on grazer foraging behavior and the drag forces imposed on the kelp thallus. One of the more striking conclusions of this study, that mortality rates of $N$. luetkeana appeared to be greatest in sites experiencing protracted periods of calm flow punctuated by episodes of intermediate-to-strong tidal currents, has led us to devise a conceptual model of interactions among grazers, their algal prey, and the hydrodynamic regime to which both are exposed. The main concepts underlying this model are illustrated in Fig. 10.

We assume that the breaking force $\left(F_{\mathrm{b}}\right)$ of a plant declines monotonically with increasing mechanical damage inflicted by mesograzers such as Lacuna vincta. The product of the number of grazers on a plant and the time during which grazers can forage (i.e. between strong flow events which may remove them or impede their foraging: Fig. 8) would be compara-

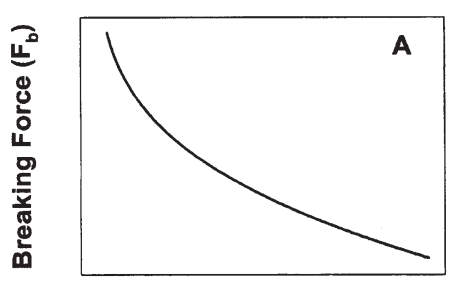

Grazer * Minutes

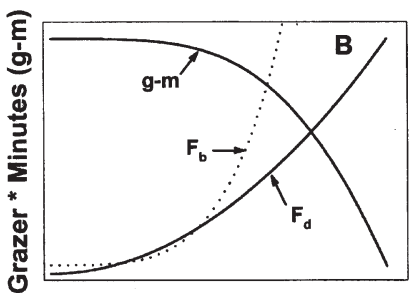

Current Speed

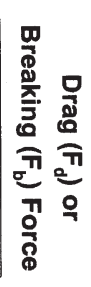

Fig. 10. Conceptual model of interactions among kelps, grazing intensity and flow characterizing a site. (A) Predicted relationship between grazing intensity and plant breaking force; (B) predicted relationships between characteristic flow energy of the site, and grazing intensity $(g-m)$, drag force experienced by a plant $\left(F_{\mathrm{d}}\right)$, and plant breaking force $\left(F_{\mathrm{b}}\right)$; $(\mathrm{C})$ predicted relationship between flow energy at a site (current speed) and the ratio of drag force to breaking force of plants ( $\alpha P$ mortality: maximum probability of mortality) 
tively simple to measure and may relate to the amount of grazer damage in a reasonably straightforward fashion. Given our results (Fig. 9 and above), which show that even minor scoring of stipes causes a significant decrease in breaking force but that $\sim 2 \times$ deeper cuts do not necessarily significantly reduce the breaking force further we suspect that the shape of the function relating $F_{\mathrm{b}}$ to grazing intensity may be non-linear and convex downward (Fig. 10A).

Our model next recognizes that the intensity and pattern of flow energy at a site will determine both the maximum drag forces and intensity of grazing to which plants are subjected. For graphical simplicity we express the critical hydrodynamic properties of the site in terms of a single variable - current speed (Fig. 10B) (see discussion above). The maximum drag force $\left(F_{\mathrm{d}}\right)$ imposed on a plant will vary with the square of the maximum flow speed to which the plant is exposed (Schlichting 1979, Vogel 1981) (Fig. 10B). The time available for grazing, one of the 2 components of our metric for grazing intensity, will depend on the length of time separating periods of intermediate-to-strong flow (Fig. 2), and we assume, based on the results of our flume study that grazing intensity will fall off rapidly above some threshold of flow energy that limits grazer foraging (Fig. 10B).

The relationship between flow energy and grazing intensity (Fig. 10B) leads directly to a prediction (based on the relationship illustrated in Fig. 10A) of how plant breaking force $\left(F_{\mathrm{b}}\right)$ varies with flow energy (Fig. 10B). The ratio of drag force to this predicted breaking force achieves a maximum value at intermediate levels of flow energy (Fig. 10C). This ratio should relate directly to the probability of mortality ( $\left.P_{\text {mortality }}\right)$ of the plant.

Members of a plant population at any site will vary in size (and therefore exposure to flow) and structural composition, and numbers of grazers on plants will vary within the population. For these reasons the population, (as opposed to an individual), response will vary in a wide envelope around the curves in Fig. 10. It is the proportion of this envelope falling above $F_{\mathrm{d}} / F_{\mathrm{b}}=$ 1 in Fig. 10C (i.e. the proportion of the plant population for which maximum drag force exceeds breaking force) that determines the proportion of the population that should be removed. Thus, our conceptual model leads to the conclusion (Fig. 10C) reflected in our data (Fig. 5), that the highest rates of plant mortality may occur in sites of intermediate flow energy.

This model prediction and our empirical data on mortality of Nereocystis luetkeana stand in contrast to the paradigm, largely established from studies of populations of Macrocystis pyrifera along exposed coastlines, which suggests that intense storms are the major cause of losses of kelp populations (e.g. see review by Dayton 1985, Seymour et al. 1989). Our data indicate that storm-generated waves were obviously not important to $N$. luetkeana populations in the region of the San Juan Archipelago during the winter of 1995, but rather that mortality rates of this surface canopy species were more impacted by the complex interaction between mesograzer activity and exposure to tidal currents.

Despite the concordance of our model predictions and empirical results (Figs $5 \& 10 \mathrm{C}$ ), it became apparent to us in devising this conceptual model that the shape of the curve in Fig. $10 \mathrm{C}$ depends critically on the relationships between grazing intensity and plant breaking force (Fig. 10A), and the relationship between grazing intensity and the intensity and pattern of flow energy (Fig. 10B: $g$-m curve ). This realization highlights the potential importance of grazing intensity in determining patterns of plant mortality among sites subjected to a range of flow energies, and also the need to accurately and quantitatively define the suite of relationships illustrated graphically in Fig. 10.

Although devised to relate to observed patterns of mortality among Nereocystis luetkeana populations, we suspect that there may be a far broader generality to this conceptual model of interactions among grazers, their algal prey, and the hydrodynamic regime to which both are exposed. We can envision these processes interacting similarly in subtidal, subsurfacecanopy communities (e.g. the Agarum spp. - Laminaria spp. assemblage that dominates shallow rocky platforms in the San Juan Archipelago), open-coast surface-canopy assemblages dominated by wave surge (e.g. Macrocystis spp. populations), and any system where consumers potentially compromise their sessile prey's attachment to the substrate. Our data and conceptual model indicate that interactions between flow energy and grazers that typically inflict sub-lethal mechanical damage may play important roles in plant population dynamics in diverse marine environments.

\section{LITERATURE CITED}

Black R (1976) The effects of grazing by the limpet Acmaea insessa on the kelp Egregia laevigata in the intertidal zone. Ecology 57:265-277

Black R, Peterson CH (1987) Biological vs. physical explanations for the non-random patchy pattern of host occupation by a macroalga attaching to infaunal bivalve molluscs. Oecologia 73:213-221

Dayton PK (1985) Ecology of kelp communities. Ann Rev Ecol Syst 16:215-245

Dayton PK, Tegner MJ (1984) Catastrophic storms, El Niño, and patch stability in a southern California kelp community. Science 224:283-285

Denny M, Brown V, Carrington E, Kraemer G, Miller A (1989) Fracture mechanics and the survival of wave-swept macroalgae. J Exp Mar Biol Ecol 127:211-228

DeWreede RE, Ewanchuk P, Shaughnessy F (1992) Wound- 
ing, healing and survivorship in three kelp species. Mar Ecol Prog Ser 82:259-266

Ebling AW, Laur DR, Rowley RJ (1985) Severe storm disturbance and reversal of community structure in a southern California kelp forest. Mar Biol 84:287-294

Foster SA (1987) The relative impacts of grazing by Caribbean coral reef fishes and Diadema: effects of habitat and surge. J Exp Mar Biol Ecol 105:1-20

Friedland MT, Denny MW (1995) Surviving hydrodynamic forces in a wave-swept environment: consequences of morphology in the feather boa kelp, Egregia menziesii (Turner). J Exp Mar Biol Ecol 190:109-133

Garbary DJ, Kim KY, Klinger T, Duggins DO (1999) Red algae as hosts for endophytic kelp gametophytes. Mar Biol 135:35-40

Grime JP (1981) Plant strategies and vegetation processes. Wiley, New York

Kawamata S (1998) Effect of wave-induced oscillatory flow on grazing by a subtidal sea urchin Strongylocentrotus nudus (A. Agassiz). J Exp Mar Biol Ecol 224:31-48

Kennelly SJ (1987) Physical disturbances in an Australian kelp community. II. Effects on understory species due to differences in kelp cover. Mar Ecol Prog Ser 40:155-165

Koehl MAR, Alberte RS (1988) Flow, flapping, and photosynthesis of Nereocystis luetkeana: a functional comparison of undulate and flat blade morphologies. Mar Biol 99: 435-444

Koehl MAR, Wainwright SA (1977) Mechanical adaptations of a giant kelp. Limnol Oceanogr 22:1067-1071

Maxell BA, Miller KA (1996) Demographic studies of Nereocystis luetkeana and Costaria costata (Laminariales, Phaeophyta) in Puget Sound, Washington. Bot Mar 39: 479-489

McQuaid CD, Branch GM (1985) Trophic structure of rocky intertidal communities: response to wave action and implications for energy flow. Mar Ecol Prog Ser 22:153-161

Menge BA (1978a) Predation intensity in a rocky intertidal community. Effect of an algal canopy, wave action and desiccation on predator feeding rates. Oecologia 34:17-35

Editorial responsibility: Charles Peterson (Contributing Editor), Morehead City, North Carolina, USA
Menge BA (1978b) Predation intensity in a rocky intertidal community. Relation between predator foraging activity and environmental harshness. Oecologia 34:1-16

Peterson CH (1979) The importance of predation and competition in organizing the intertidal epifaunal communities of Barnegat Inlet, New Jersey. Oecologia 39:1-24

Robles CD (1997) Changing recruitment in constant species assemblages: implications for predation theory in intertidal communities. Ecology 78:1400-1414

Robles C, Robb J (1993) Varied carnivore effects and the prevalence of intertidal algal turfs. J Exp Mar Biol Ecol 166:65-91

Sanford E (1999) Regulation of keystone predation by small changes in ocean temperature. Science 283:2095-2097

Santelices B, Castilla J, Cancino J, Schmiede P (1980) Comparative ecology of Lessonia nigrescens and Durvillaea antarctica (Phaeophyta) in central Chile. Mar Biol 59: 119-132

Schlichting H (1979) Boundary layer theory. McGraw-Hill, New York

Seymour RJ, Tegner MJ, Dayton PK, Parnell PE (1989) Storm wave induced mortality of giant kelp, Macrocystis pyrifera, in southern California. Estuar Coast Shelf Sci 28: $277-292$

Sokal RR, Rohlf FJ (1981) Biometry. The principles and practice of statistics in biological research, 2nd edn. WH Freeman \& Co, New York

Tegner MJ, Dayton PK, Edwards PB, Riser KL (1995) Sea urchin cavitation of giant kelp (Macrocystis pyrifera C. Agardh) holdfasts and its effects on kelp mortality across a large California forest. J Exp Mar Biol Ecol 191:83-99

Utter BD, Denny MW (1996) Wave-induced forces on the giant kelp Macrocystis pyrifera: field test of a computational model. J Exp Biol 199:2645-2654

Vogel S (1981) Life in moving fluids. Princeton University Press, Princeton, NJ

Witman JD, Grange KR (1998) Links between rain, salinity, and predation in a rocky subtidal community. Ecology 79:2429-2447

Submitted: February 7, 2000; Accepted: December 31, 2000 Proofs received from author(s): September 26, 2001 